\title{
Uma proposta para o processo de definição do estoque de segurança de itens comprados em empresas que fabricam produtos complexos sob encomenda
}

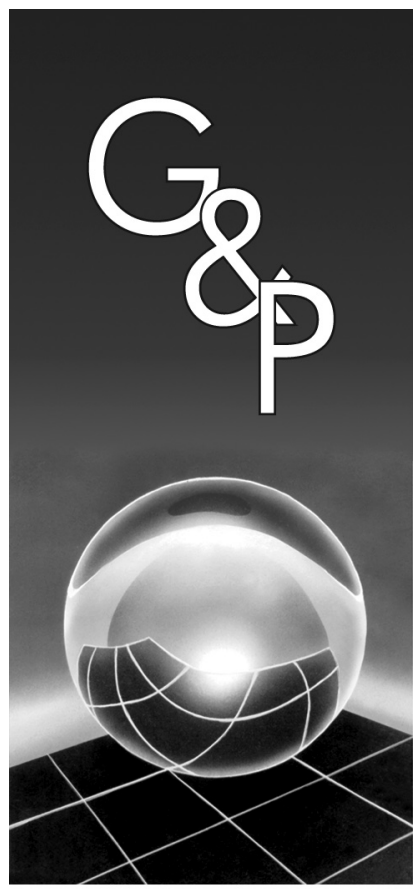

João Henrique Lopes Guerra
Resumo

A definição do Estoque de Segurança costuma seguir critérios puramente qualitativos, muitas vezes sem nenhum fundamento ou puramente quantitativos, em que o conhecimento de pessoas-chave não é aproveitado. Com base na experiência prática do autor e com o apoio da literatura, propõe-se neste trabalho um modelo para a definição deste parâmetro com base nestes dois critérios, conjuntamente. Espera-se que ele possa subsidiar as decisões relacionadas à definição do Estoque de Segurança de itens comprados em empresas que fabricam produtos complexos sob encomenda, nas quais este tipo de item responde pela maior parte do custo do produto final. Incertezas existentes nos ambientes interno e externo destas empresas tornam necessário este tipo de estoque em muitas situações.

Palavras-chave: Estoque de Segurança. Produção sob encomenda. Produtos complexos.

\section{Introdução}

O entendimento de um sistema organizado passa necessariamente pela constatação de que um fluxo de recursos é sempre acompanhado por um fluxo de informação responsável pelo seu controle. A evolução dos sistemas produtivos e, de forma mais geral, das próprias estruturas administrativas das empresas, consubstanciadas nas mudanças estratégicas que suas principais funções (marketing, produção, compras, etc.) têm sofrido ao longo do tempo, trouxe como resultado uma crescente necessidade de acesso a informações integradas.

Os sistemas MRP (Material Requirements Planning) e MRP II (Manufacturing Resources Planning), que apareceram respectivamente nas décadas de 60 e 80 (HOPP; SPEARMAN, 2004), passando para um novo estágio do seu processo evolutivo, transformaram-se mais recentemente, na década de 90 , em um sistema completo de gestão da empresa, agregando ao planejamento dos materiais e dos recursos relacionados à capacidade produtiva um leque de opções que permite o armazenamento, a geração e o gerenciamento de informações relacionadas a todos os recursos e funções da empresa. Os sistemas ERP (Enterprise Resources Planning; ver, por exemplo: CORREAA; GIANESI; CAON, 2007), da mesma forma como ocorreu com os dois anteriores, têm sofrido ampla disseminação em todo o mundo, contribuindo para que as empresas que os desenvolvem e os comercializam estejam situadas entre as de maiores receitas na indústria de software (caso da SAP e da Oracle).

Os benefícios potenciais relacionados ao uso de um sistema ERP, incluindo o aumento da lucratividade da empresa (HENDRICKS; SINGHAL; STRATMAN, 2007), não dependem apenas de um bom orçamento disponível e de um processo de implantação bem planejado e executado, pois este processo, embora geralmente árduo, é completado em alguma data e o sistema, então, é colocado em operação.

Uma questão crítica durante a implantação do sistema refere-se à qualidade dos dados (XU et al., 2002). Estando o sistema já implantado, esta questão perdura (PARKY; KUSIAK, 2005). Durante a operação, um calcanhar de Aquiles refere-se ao processo de manutenção (ou atualização) dos dados que funcionam como combustível do sistema. Englobam-se neste processo todas as atividades necessárias para garantir a qualidade destes dados, sem os quais as informações de saída do sistema deixariam de ser válidas (confiáveis). Neste contexto, cabem duas observações: a primeira é que este processo, nos casos em que depende de atividade humana, pode ser vulnerável e complexo; a 
segunda é que, intrinsecamente relacionada ao processo, existe uma decisão sobre a frequência da atualização dos dados. Um caso clássico refere-se ao parâmetro Estoque de Segurança (ES).

Quando uma empresa decide manter um ES, na prática o que ela está decidindo é obter do fornecedor (no caso de itens comprados) uma quantidade além daquela necessária para atender à demanda planejada e que será usada no caso de ocorrer alguma eventualidade (caso o consumo seja maior do que o planejado, por exemplo).

No caso de empresas que fabricam produtos complexos sob encomenda (portanto, o plano de produção é baseado em informações confiáveis obtidas a priori, não em previsão), o fato de conhecerem a demanda dos seus produtos finais permite que a demanda dos seus componentes também seja conhecida (determinística). No entanto, isto não significa que esta demanda não esteja sujeita a uma série de incertezas. Na prática, estas incertezas podem ter três causas: o ambiente externo (uma crise econômica pode forçar os clientes a reduzirem o número de pedidos já firmados, ou a solicitarem a postergação das entregas); o cliente (quando solicita uma mudança da configuração final do produto, quando este já está em produção ou a cadeia de suprimentos já foi acionada para suprir os componentes opcionais originais que ele especificou); e o fabricante (quando faz uma alteração tardia, mas necessária, na estrutura de produto). Para muitas empresas, estas situações estão longe de serem raras na prática, o que gera a necessidade de lançar mão de um ES para muitos componentes.

Assim, no contexto das empresas que fabricam produtos complexos sob encomenda, é imprescindível um processo de definição do ES robusto, considerando que neste tipo de empresa os itens comprados representam a maior parte do custo do produto final.

\section{A definição do Estoque de Segurança nas empresas}

Diferentes abordagens podem ser utilizadas para a definição do ES: desde uma decisão sem nenhum fundamento, apenas travestida de feeling, passando por definições de estoque baseadas na experiência (LEMOS; FOGLIATTO, 2004; MACIEIRA et al., 2004) até um complexo cálculo analítico (HUMAIR; WILLEMS, 2006; VANTEDDU et al., 2007). O ponto a destacar é que, em muitas situações, os sistemas ERP tratam o parâmetro ES como um dado de entrada, o que exige uma decisão humana sobre qual dado carregar no sistema. Em outras, ainda que o sistema possa calculá-lo, podem existir outros entraves:

- A qualidade e a quantidade de dados necessários para o sistema realizar o cálculo segundo sua lógica, tanto em termos da diversidade de dados, quanto do período histórico mínimo que deve estar disponível;
- O raciocínio usado no cálculo pode estar escondido na caixa preta que são os softwares proprietários, o que acaba gerando uma desconfiança do usuário no que se refere ao cálculo feito pelo sistema, principalmente no caso de itens mais caros.

Apesar da importância do papel do ES na satisfação do cliente em ambientes com incertezas internas e externas (VANTEDDU et al., 2007), a responsabilidade pela sua definição pode variar de empresa para empresa. Nos casos dos itens comprados, que é o foco deste trabalho, as funções compras, produção ou até a logística podem agregar esta atividade. A razão de ser de cada uma delas permite um olhar sobre o item segundo um ponto de vista baseado em um conjunto particular de variáveis: a primeira adquire o item no mercado e acompanha o processo de compra até que ele esteja disponível no estoque, conhecendo as dificuldades intrínsecas ao seu processo de obtenção; a segunda é quem sofre com as dificuldades de montagem, os problemas de qualidade e o impacto da falta do item; já a última conhece os custos logísticos e aqueles associados à manutenção do item em estoque e sofre as consequências dos excessos de estoque.

O parâmetro ES e mais um conjunto de outras informações são tratados pelo sistema ERP que, por fim, irá sugerir ordens de compra a serem efetivadas ao longo do tempo. Assim, a função responsável por analisar estas sugestões e tomar a decisão de aceitá-las ou não é a usuária do parâmetro, pois é ela quem efetivamente está decidindo e agindo no sentido de transformar o parâmetro cadastrado no sistema em um estoque físico. Em uma situação bastante comum nas empresas, esta atividade costuma ficar com a função compras. Desta forma, na prática o processo de definição segue geralmente um de dois modelos: no primeiro, uma área qualquer define o ES (exemplo: uma área dentro da função produção) e carrega o dado no sistema, sendo uma outra área usuária deste parâmetro (exemplo: uma área dentro da função compras); no segundo, a área usuária é a mesma que define o valor do parâmetro. Estes dois modelos podem apresentar problemas.

Nos dois casos, a área responsável pela definição do parâmetro pode não ter acesso a todos os dados e informações necessárias para uma definição adequada do ES. Mesmo que tenha, muitas informações, de ordem mais qualitativa, exigem um conhecimento tácito para interpretá-las e transformá-las em insumos úteis que poderiam favorecer a qualidade do parâmetro. Considerando que estas informações estão relacionadas a diversas incertezas que tornam o ES necessário, mas que costumam estar associadas a diferentes áreas, a competência para interpretá-las pode estar distribuída em diferentes funções da empresa. Além disso, a área que está incumbida de definir o parâmetro pode, por desconhecimento, deixar de considerar variáveis que são significativas para outras áreas, mas que são transparentes para ela. 
O primeiro modelo pode apresentar um problema adicional. Dependendo da maneira como o processo é conduzido, principalmente no que se refere ao interrelacionamento entre as áreas durante o processo de definição do ES, caso ocorra excesso de estoque ou falta, a área usuária do parâmetro pode sentir que um parâmetro com qualidade duvidosa está sendo imposto a ela. Isto pode levar a área usuária a tomar decisões unilaterais.

No contexto desta discussão, este trabalho defende dois pressupostos: o primeiro é que o processo de definição do parâmetro ES, pelo menos quando envolve itens caros e ambientes mais complexos, deve ser multifuncional; depois, que é imprescindível que o usuário (a pessoa, não a função) do parâmetro tenha consciência e segurança do processo que foi utilizado na sua definição, ainda que e principalmente se ele não tenha participado dele. Pode não parecer uma boa ideia para um comprador confiar em um parâmetro definido por terceiros e por meio de critérios desconhecidos, pois, neste caso, o valor do parâmetro torna-se algo subjetivo, ao passo que ele tem seu trabalho medido por indicadores bastante claros. Em uma empresa que demanda milhares de itens diferentes e em que cada comprador tem sob sua responsabilidade a compra de centenas ou até milhares deles, fica muito difícil identificar uma falta de aderência da decisão do comprador em relação ao parâmetro cadastrado no sistema. Assim, ganhar a confiança dele em relação ao parâmetro cadastrado é fundamental.

\section{A proposta no contexto dos conceitos japoneses de redução de estoque}

Durante as décadas de 70 e 80, particularmente após a primeira crise do petróleo em 1973, a elevada competitividade dos produtos japoneses chamou a atenção do ocidente para os modelos japoneses de gestão. O mais famoso deles, $\mathrm{O}$ Sistema Toyota de Produção (ou Lean Production; ver HOLWEG, 2007), é em essência um sistema de eliminação de perdas, sendo a eliminação dos estoques um dos seus pilares fundamentais. O Just in Time (JIT) representa a sua principal estratégia para a redução dos estoques, utilizando para isso diferentes técnicas, entre elas a produção puxada via kanban (ver SHINGO, 1996). Neste tipo de produção, a ênfase é colocada na redução dos níveis de estoque em cada etapa do processo produtivo. Um grande esforço é dedicado à eliminação de problemas, de modo a reduzir ao máximo o risco de interrupções no fluxo produtivo.

Ao analisar um modelo japonês como o STP no seu todo, fica difícil rotulá-lo como "técnica" ou "ferramenta", ainda que ele utilize um conjunto destes substantivos para alcançar seus objetivos. Por causa da amplitude do seu escopo, atualmente ele pode ser considerado, como muitos autores afirmam, uma filosofia. Observado por esta ótica, seus conceitos passam a ser uma referência cuja validade transcende funções, indústrias e até mesmo os outros modelos de gestão existentes. Assim, ainda que uma empresa adote, por exemplo, um sistema como o MRP, ela pode usar vários conceitos do STP para melhorar seu desempenho.

Neste contexto, falar em ES atualmente pode parecer um contrassenso, na medida em que isto significa manter estoque. Mas não é bem assim. Existem várias situações em que uma empresa não consegue ter controle sobre todas as variáveis que provocam algum tipo de incerteza, seja em seu ambiente interno, seja (principalmente) no externo (ver, por exemplo: MACIEIRA et al., 2004). Nestes casos, o estoque é necessário porque permite compatibilizar o fornecimento com a demanda. É o caso de indústrias com cadeias de suprimentos muito internacionalizadas, nas quais os longos ciclos logísticos que separam o fabricante dos seus fornecedores geram uma incerteza que força o uso do ES. Assim, salvo aquelas situações em que a empresa mantém estoques por motivos especulativos, o que determina a necessidade do ES é o conjunto de variáveis que influenciam o cenário atual da empresa, e não o seu modelo de gestão. Não obstante, este trabalho considera imprescindível a atuação da empresa na causa das incertezas, visando à possibilidade dos níveis de estoque serem reduzidos.

\section{Produtos complexos fabricados sob encomenda}

A proposta aplica-se a empresas que fabricam produtos altamente complexos, sob diferentes perspectivas. As principais características destes produtos são:

- Alto valor agregado, principalmente devido ao seu conteúdo tecnológico;

- Estrutura de produto altamente complexa, tanto em termos do número de níveis quanto de itens diferentes;

- Make-to-order (fabricação contra pedido; ver WEMMERLÖV, 1984);

- Existência de certo grau de customização na sua configuração final, já que partes específicas da estrutura de produto estão relacionadas a pacotes de componentes opcionais definidos pelo cliente no momento da compra;

- Baixa cadência produtiva (de algumas unidades até poucas dezenas por mês);

- Longos lead-times de fabricação (variando de algumas semanas até vários meses);

- Apresentam mão de obra intensiva em algumas etapas do seu processo produtivo; e

- Cadeia de suprimentos complexa, geralmente bastante internacionalizada, principalmente no caso dos componentes mais críticos.

A proposta se aplica aos produtos que, mesmo produzidos sob encomenda e com um grau de customização, atendem ao mercado geral. Portanto, não engloba aqueles desenvolvidos 
e produzidos para atender um cliente específico (o que caracterizaria um processo engineering-to-order; ver MARUCHECK; McCLELLAND, 1986), com um número pré-estabelecido de unidades a serem produzidas.

Evidentemente, nem todas as características anteriores precisam estar presentes no produto para a proposta tornar-se válida. O ponto a destacar é que estas características conferem aos produtos um conjunto de incertezas associadas ao seu desenvolvimento, processo produtivo e cadeia de suprimentos. Como exemplo, os seguintes produtos podem ser citados: bens de capital, ônibus, aviões de médio e grande porte (ou seja, aqueles que atendem às linhas regionais e principais, bem como o mercado executivo), trens, alguns produtos do setor elétrico (como alguns tipos de geradores de médio e grande porte), alguns produtos da indústria naval (como as embarcações de menor porte), entre outros. Pela classificação de Fisher (1997), estes produtos podem ser considerados inovadores.

\section{Proposta de um modelo para a definição do Estoque de Segurança}

\subsection{A definição do ES entendida como um processo}

O modelo proposto foi desenvolvido para atender aos itens comprados, ou seja, obtidos de fonte externa à empresa (fornecedores). Nele, a definição do ES é entendida como um processo formal. É um processo porque possui dados e informações de entrada, algumas etapas de transformação destes dados e informações e, como saída, uma decisão sobre o cadastro do parâmetro ES no sistema da empresa (ERP, por exemplo). Deve ser formal basicamente por três motivos: (i) por ser um processo periódico (e não uma rotina contínua), ele exige um planejamento antecipado (quem, quando, como); (ii) as responsabilidades e os papéis de cada um no processo devem estar claros, estando sua execução sob a gestão de um cargo do médio escalão (um gerente funcional, por exemplo) e seus resultados acompanhados de perto pela alta direção; e (iii) o último motivo justifica a necessidade deste acompanhamento: estes itens envolvem grandes somas de dinheiro porque respondem pela maior parte do custo dos produtos finais (HORNG, 2007) que são o foco desta proposta. Se a falta deles pode trazer enormes prejuízos ao processo produtivo e ao atendimento ao cliente, o mesmo pode acontecer com uma gestão de estoque deficiente, considerando que os estoques destes itens podem ficar na casa das dezenas e até das centenas de milhões de reais.

\subsection{As etapas do processo}

Pela Figura 1, o modelo possui uma etapa quantitativa, duas qualitativas, uma etapa de contato com o fornecedor e cadastro do parâmetro e, por fim, uma de monitoramento.
Ao se tentar traduzir para uma análise puramente quantitativa (um cálculo estatístico, por exemplo) todas as variáveis existentes nos ambientes interno e externo à empresa que podem ter alguma influência na decisão sobre qual ES adotar para cada item, não é difícil imaginar que, mesmo que isso fosse possível, ela ficaria tão complexa que dificultaria sua operacionalização. A quantidade e a qualidade dos dados poderiam inviabilizar o processo ou torná-lo muito demorado ou custoso. Esta complexidade também dificultaria a manutenção do parâmetro (sua revisão periódica) no sistema da empresa, assim como poderia comprometer a confiança que os usuários diretos (compradores, por exemplo, que respondem pelas faltas, mas não costumam ser especialistas em análises quantitativas) devem ter no parâmetro. Por outro lado, uma análise puramente qualitativa pode ser muito subjetiva.

Neste contexto, a proposta busca aproveitar os dois tipos de análise: um cálculo do ES, obtido por meio de uma análise quantitativa, torna-se o ponto de partida para que, posteriormente, ele receba a análise crítica de pessoas-chave.

Considerando que os fatores (quantitativos ou qualitativos) que influenciam uma decisão sobre ES são variáveis (e não constantes), este parâmetro precisa ser revisado periodicamente. Sugere-se uma revisão semestral. Revisões muito frequentes podem gerar um nervosismo desnecessário no sistema de gestão da empresa e na cadeia de suprimentos. Por outro lado, revisões pouco frequentes podem fazer com que o dado cadastrado no sistema fique defasado em relação ao status atual das variáveis que influenciam o ES (o ES cadastrado pode refletir uma dificuldade de montagem que existia, mas que já foi solucionada há meses, por exemplo).

Porém, fatos importantes que ocorrerem durante as revisões planejadas podem servir como gatilho para uma nova revisão do ES. Uma alteração nas estratégias competitiva ou funcional, assim como uma mudança significativa em alguma variável importante usada na definição do parâmetro são exemplos de eventos que justificam uma revisão adicional.

\subsubsection{Cálculo do Estoque de Segurança}

Os responsáveis por esta etapa precisam ter familiaridade com os métodos analíticos disponíveis para o cálculo do ES, devem fazer a coleta dos dados necessários ao cálculo (obtidos do sistema da empresa) e ter segurança sobre a confiabilidade destes dados. Independentemente da função a que estas pessoas possam pertencer ou do seu nível de competência nestes métodos (métodos quantitativos mais simples podem ser empregados em muitos casos), neste trabalho elas são designadas por especialistas em análises quantitativas.

A escolha do método depende das particularidades da empresa e da situação. A seguir será apresentado um deles, baseado em fórmulas estatísticas consolidadas na literatura. Estas fórmulas tratam de forma isolada e em 


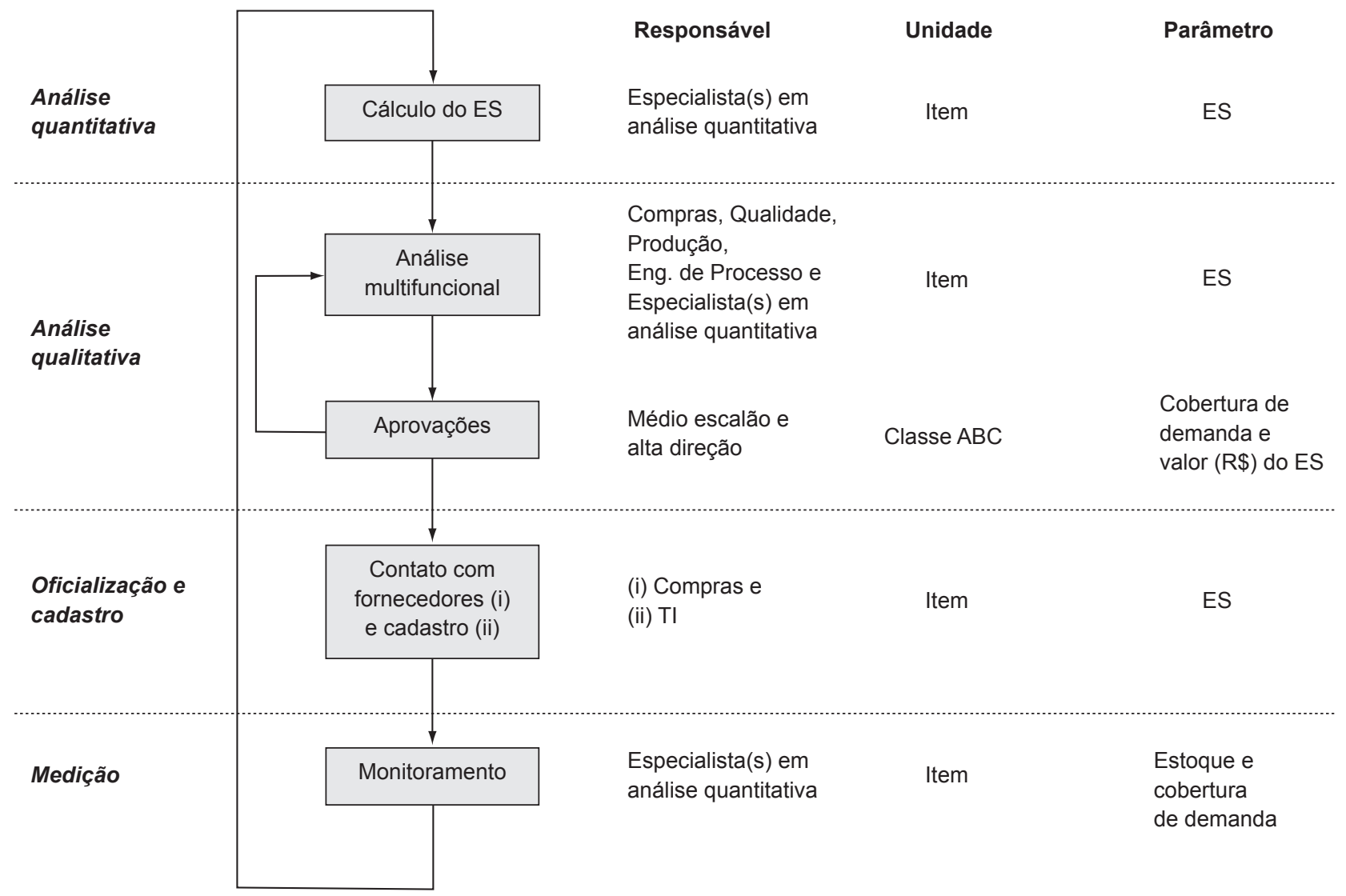

Figura 1. Modelo para a definição do parâmetro ES (processo periódico).

conjunto as incertezas que geram a necessidade de ES, definindo uma quantidade de ES para cada item segundo um nível de serviço desejado.

$\mathrm{Na}$ prática, as diferentes incertezas que podem gerar a necessidade de ES podem ser agrupadas em três grupos: incerteza do lead-time (atraso do fornecedor, ciclos logísticos maiores do que o planejado, etc.); incerteza da demanda (refugos, demanda real maior do que a planejada, etc.); e incerteza da quantidade recebida (recebimento de uma quantidade diferente da comprada). Ainda que em tese nenhuma incerteza devesse ser aceita (todo gerente deve buscar reduzir a influência das incertezas atuando em suas causas), a última delas é a menos aceitável porque, salvo situações específicas, ela está relacionada a posturas inadmissíveis (ou do fornecedor ou do operador logístico) no contexto competitivo atual. Assim, ela não será tratada (considera-se que ela pode ser eliminada apenas com uma exigência da empresa cliente). Para os outros dois grupos, as fórmulas correspondentes estão explicitadas a seguir (ver: STEVENSON, 2001; SANTOS; RODRIGUES, 2006; CORRÊA; CORRÊA, 2007).

Quando houver apenas a influência da incerteza da demanda, o ES é calculado com base na variação da demanda durante o lead-time do item (Equação 1):

$$
E S=F S . D P d l t
$$

$F S=$ Fator de Serviço (corresponde ao número de desvios-padrão desejado).
$D P d l t=$ Desvio-padrão dos erros de previsão (diferença entre as demandas planejada e real) no lead-time.

Mas o lead-time pode ter um período diferente daquele do histórico disponível para as demandas planejada e real. Exemplo: o lead-time pode ser de quatro meses e o histórico da demanda, mensal. Neste caso, pode-se utilizar uma propriedade da variância para adaptar a fórmula: a variância de um período $T 1=T 2+T 3$ é igual à variância do período $T 2$ mais a variância do período T3. Portanto, sendo o desvio-padrão igual à raiz quadrada da variância, no exemplo dado DPdlt pode ser calculado tirando-se a raiz quadrada da soma da variância de cada um dos quatro meses que compõem o lead-time. Adotando-se que a variância seja a mesma em todos os meses (trata-se de uma aproximação, mas aceitável em muitas situações), fica (Equação 2):

$$
\begin{aligned}
D P d l t & =\sqrt{(D P d)^{2}+(D P d)^{2}+(D P d)^{2}+(D P d)^{2}}= \\
& =D P d . \sqrt{4}
\end{aligned}
$$

$D P d=$ Desvio-padrão dos erros de previsão (diferença entre as demandas planejada e real) no período considerado (ou seja, no período a que se referem os dados históricos das demandas planejada e real). 
Usando-se este raciocínio para uma situação geral, tem-se (Equação 3):

$$
D P d l t=D P d \cdot \sqrt{L T}
$$

O que leva à fórmula final (Equação 4):

$$
E S=F S . D P d \cdot \sqrt{L T}
$$

$L T=$ Lead-time (na mesma unidade de tempo dos dados históricos usados para o cálculo do desvio-padrão; por exemplo: semana ou mês).

Quando houver apenas a influência da incerteza do lead-time, o cálculo de DPdlt fica (Equação 5):

$$
\text { DPdlt }=\text { DPlt . D }
$$

$D P l t=$ Desvio padrão do lead-time .

$D=$ Demanda.

Portanto, o cálculo do ES para esta situação fica (Equação 6):

$$
E S=F S . D P l t . D
$$

Neste caso, como só existe a incerteza do lead-time, as demandas planejada e real são iguais. Porém, a fórmula anterior aplica-se ao caso em que a demanda é constante. Em uma situação de demanda variável, ela poderia ser adotada usando-se uma demanda média, no entanto esta seria uma aproximação que faria sentido apenas se a variação da demanda ao longo do tempo fosse muito pequena (como o caso de um produto com uma cadência produtiva já em regime, durante a etapa de maturidade do seu ciclo de vida).

Quando houver a influência tanto da incerteza da demanda quanto do lead-time, podem-se elevar os desvios-padrão das Equações 3 e 5 ao quadrado, obtendo-se as respectivas variâncias que são posteriormente somadas e, por fim, é tirada a raiz quadrada para a obtenção do desvio-padrão, gerando a seguinte fórmula (Equação 7):

$$
E S=F S . \sqrt{L T \cdot D P d^{2}+D^{2} \cdot D P l t^{2}}
$$

\subsubsection{Análise multifuncional do Estoque de Segurança calculado}

Não se pode desprezar a opinião de pessoas que possuem experiência nos itens comprados, mesmo que estas pessoas não conheçam os pormenores dos métodos quantitativos empregados em um cálculo de ES. Por outro lado, como esta experiência está em muitas vezes sob a forma de conhecimento tácito, difícil de ser transferido ou quantificado, ela pode ser aproveitada por meio de uma análise qualitativa.

Aqui, o ES calculado na etapa anterior é avaliado por um grupo multifuncional composto pelas seguintes áreas: compras, qualidade, produção, engenharia de processo e mais um (ou mais) representante da etapa anterior. Observações: (i) havendo representantes dos fornecedores na empresa, estes também podem participar; (ii) um representante de cada área costuma ser suficiente.

Além de apresentar todo o processo da etapa anterior e seus resultados para o grupo multifuncional, o representante da etapa anterior (o especialista na análise quantitativa) também participa da análise nesta segunda etapa. Apesar de (poder) não ter competência técnica, o fato de ter os detalhes dos dados usados no cálculo do ES enriquece a análise, tornando as decisões mais robustas. A importância do seu papel reside no fato dele ser o ponto de intersecção entre as análises quantitativa e qualitativa.

As análises ocorrem por meio de uma ou algumas reuniões formais (exclusivas para o assunto) nas quais o grupo analisa criticamente o ES calculado para parte dos itens. Como o número de itens pode ser grande, o grupo deve focar a análise nos mais importantes, ou seja: os itens classe A, parte dos classe B (exemplo: pode-se dividir estes itens em uma nova classe $\mathrm{ABC}$ e escolher os classe $\mathrm{A}$; sobre a classificação ABC, ver, por exemplo: GAITHER; FRAZIER, 2002; BALLOU, 2006) e mais aqueles que estão diretamente envolvidos com algumas situações selecionadas. As situações que exigem um cuidado ainda maior na definição do ES são as seguintes (evidentemente, a lista a seguir é uma sugestão e pode ser complementada, segundo critérios do próprio grupo multifuncional):

Caminho crítico: os itens comprados usados em montagens relacionadas ao caminho crítico (ver, por exemplo: GAITHER; FRAZIER, 2002) requerem um cuidado especial porque uma falta ou atraso pode significar risco de não atendimento do prazo combinado com o cliente para o produto final. A primeira ação refere-se à identificação destes itens, pois os produtos finais tratados neste trabalho possuem uma estrutura de produto com dezenas de milhares de itens diferentes.

ES para o item ou seu componente: a análise qualitativa do ES tem entre as suas vantagens a possibilidade de compensar deficiências da análise quantitativa. Considerando-se o grande número de itens e dados envolvidos, é praticamente impossível dar um tratamento detalhado, item a item, na análise da etapa anterior. $\mathrm{Na}$ prática são usadas bases de dados de forma que todos os itens são tratados conjuntamente. Mesmo havendo cuidado com a qualidade dos dados de entrada, considerando-se que as pessoas envolvidas neste tipo de análise nem sempre têm o domínio técnico ou estão em contato direto com todos os processos que sofrem influência das incertezas que geram a necessidade do ES, alguns problemas surgem e dificilmente são identificados nesta etapa. Por exemplo: quando um subsistema sofre alguma pane e é encaminhado para a área 
de quarentena para análise (considerando-se que não seja possível resolver o problema na área produtiva), o sistema de informação da empresa, por conta dos documentos abertos pela área da qualidade, registrará que o problema ocorreu com o subsistema. Como a análise quantitativa usa as bases de dados do sistema, muito provavelmente será sugerido um ES para o subsistema que será tão maior quanto maior for a reincidência do problema (este é um caso particular de incerteza de demanda, pois o consumo do subsistema foi maior do que o planejado). No entanto, o grupo multifuncional pode identificar que na verdade a causa do problema refere-se a algum componente do subsistema, como um duto, um rolamento, uma pequena cablagem ou uma válvula. Por conta disso, o grupo pode vetar o ES para o subsistema e sugerir um ES para o componente.

ES de componentes: o grupo pode antecipar-se e definir uma lista de componentes de subsistemas importantes que precisam ter ES. Este é um tipo de situação em que a análise quantitativa em muitos casos não se aplica pela inexistência de dados, o que pode ter duas causas: não houve registro no sistema quando o problema ocorreu (por serem componentes de um subsistema) ou o problema não ocorreu ainda (mas tem probabilidade de ocorrer).

Oversize: em furações manuais é comum ocorrer que um furo fique maior do que o especificado. Neste caso, não é mais possível utilizar o hardware mecânico (rebite, parafuso, etc.) que consta na estrutura de produto. Mas a engenharia pode especificar outros hardwares mecânicos, com maiores espessuras, porém com as mesmas características mecânicas daqueles originalmente especificados. O grupo multifuncional pode então determinar uma quantidade de ES a ser mantida para cada item. Conforme vai sendo formado um histórico de consumo destes itens, passa a ser possível o cálculo do ES na etapa anterior.

ES em tempo: o grupo multifuncional pode escolher alguns itens classe A (o preço do item é o principal critério) e discutir a possibilidade de trabalhar com ES em tempo. Neste tipo de ES, nenhuma quantidade adicional (em relação à demanda planejada) é comprada (como ocorre no caso do ES em quantidade calculado na etapa anterior), mas as entregas do item são programadas para ocorrer um determinado tempo antes da data planejada. Em tese, o uso deste ES só é possível quando os itens em questão sofrerem influência apenas da incerteza de lead-time, o que limita seu escopo. Além disso, ele exige ações da função compras que devem ser sustentadas pelo sistema da empresa (assim, o sistema deve oferecer este recurso, sugerindo corretamente as ordens de compra antes da data planejada original). O cálculo do tempo de segurança pode ser feito pelos especialistas em análise quantitativa com base na distribuição (em dias) do atraso do fornecedor e da variação dos ciclos logísticos.

Itens opcionais (ES estratégico): o cliente define uma configuração do produto final pela escolha de um conjunto de itens opcionais. Parte dos itens opcionais está associada a funções básicas do produto e, por isso, o cliente deve escolher uma dentre duas ou mais alternativas. A outra parte está associada a funções complementares (como entretenimento) que o cliente escolhe levar ou não. Por serem específicos, os itens opcionais costumam ter longos lead-times de entrega e preços muito elevados. Apesar da configuração do produto final ser definida no ato da compra, não é difícil o cliente alterar a configuração quando o processo de obtenção dos insumos ou mesmo a sua fabricação já tiver sido iniciada. Uma característica das empresas que fabricam os produtos que são o foco deste trabalho explica esta prática: há um número relativamente pequeno de clientes que fazem grandes pedidos, o que significa que o poder de barganha do comprador é alto. A mudança da configuração no meio do caminho causa um grande transtorno às funções compras e produção, principalmente quando o novo pacote de itens opcionais escolhido (modificado) pelo cliente não está disponível. Visando evitar que este problema ocorra, pode-se definir um ES de itens opcionais. Este ES seria estratégico na medida em que visasse proteger a empresa quando o cliente retardasse sua decisão de configuração. Indo mais além, este ES pode permitir que a empresa intencionalmente ofereça ao cliente a possibilidade de definir a configuração mais tarde, criando um importante diferencial competitivo. Sendo esta a opção da empresa, o grupo multifuncional deve envolver as áreas de engenharia e comercial, visando definir: (i) quais são os itens opcionais; (ii) quais são as configurações possíveis e, dentre estas, quais são as mais prováveis de serem escolhidas pelos clientes (neste caso, os dados das vendas passadas e as características dos produtos já em uso pelos clientes que compõem a carteira atual da empresa podem auxiliar); e (iii) quanto manter de ES de cada item opcional. Este é outro tipo de situação em que uma análise puramente quantitativa é impossível de ser realizada sem o subsídio de uma análise técnica detalhada.

Por causa de suas funções na empresa, as pessoas que compõem este grupo multifuncional têm contato direto com as variáveis utilizadas no cálculo quantitativo da etapa anterior. Além disso, eles conhecem as condições e as situações sob as quais estas variáveis estavam sujeitas quando os dados foram coletados. Conhecem também o lado técnico dos itens, seus componentes, seus fornecedores e seus processos de obtenção, as etapas produtivas em que eles são utilizados e as respectivas dificuldades de montagem. Portanto, podem identificar e interpretar coisas que são transparentes para os métodos quantitativos.

Assim, é dada ao grupo a autonomia para alterar o ES calculado na etapa anterior, desde que haja consenso e motivos que justifiquem a decisão. Ainda assim, o grupo 
não pode simplesmente desprezar o cálculo: o objetivo é usá-lo como a referência a partir da qual o grupo irá decidir sobre uma percentagem de acréscimo ou decréscimo no ES calculado, de forma consciente e com base na experiência coletiva do grupo.

Por não envolver uma decisão do tipo "sim/não" ou "a favor/contra", mas, ao contrário, envolver uma decisão sobre uma percentagem, as reuniões costumam fluir sem grandes dificuldades (pode ser muito difícil convencer uma pessoa a mudar sua opinião de "contra" para "a favor", mas é mais fácil convencê-la a diminuir um ES de $10 \%$ para 20\%). Ainda assim, é importante que uma das pessoas (escolhida pelo grupo) assuma o papel de mediador, com uma postura neutra, mas presente o suficiente para fazer todos os participantes explicitarem seus pontos de vista e direcionar um consenso. Desta forma, o papel do mediador é manter a reunião em um nível colaborativo.

Além da análise do ES calculado, as reuniões que ocorrem durante esta etapa devem servir para definir ações diretamente relacionadas com as incertezas que geram a necessidade do ES, como a melhoria de um processo, treinamentos, contato com o fornecedor, etc., o que pode favorecer sua redução ou eliminação futura. Como o grupo prioriza, entre outros, os itens mais caros, esta etapa é fundamental porque funciona como um comitê no qual são definidas ações diretas para itens específicos.

\subsubsection{Aprovações}

$\mathrm{Na}$ primeira etapa foi feita uma análise teórica que resultou em uma proposta de ES baseada no nível de serviço desejado. Na etapa seguinte esta proposta foi analisada qualitativamente pelo grupo multifuncional, principalmente usando critérios mais técnicos. Em ambas as etapas a análise teve como preocupação principal a quantidade (número) a ser cadastrada como ES no sistema, para cada item.

Apesar do grupo multifuncional ter a sensibilidade do preço dos itens e, por conta disso, poder usar esta informação para "pesar" suas decisões, nenhuma análise financeira foi realizada até o momento. Isto é feito na terceira etapa. Para isso, a proposta resultante da análise do grupo multifuncional, item a item, é traduzida para unidades mais agregadas visando sofrer a análise de dois outros grupos: (a) primeiramente a proposta é apresentada aos gerentes funcionais do médio escalão envolvidos diretamente com os itens (por exemplo: compras e produção); e (b) após a proposta ter sido aprovada pelo grupo anterior, ela é enviada para a validação da alta direção (diretores e/ou vice-presidentes).

O principal objetivo desta etapa - que na prática acontece por meio de duas reuniões formais - é realizar uma análise do impacto financeiro da revisão do ES. Mas além do custo, estes dois grupos também devem observar qual seria a cobertura de demanda que o ES daria à empresa se a proposta fosse implementada. A cobertura de demanda do ES é uma medida simples, mas muito ilustrativa que mostra quanto tempo de demanda o ES conseguiria atender, se houvesse uma interrupção completa do abastecimento. Sugere-se aqui que ela seja calculada dividindo-se o ES (em quantidade) pela demanda média futura do item. Devido às características dos produtos que estão no contexto deste trabalho, a demanda média futura (semanal ou mensal, por exemplo) pode ser calculada considerando-se um horizonte de seis meses a um ano, visando reduzir a influência de picos ou quedas localizadas da demanda.

A Figura 2 mostra três gráficos que podem ser usados como modelos para a análise. Podem ser criados gráficos por tecnologia (hardware elétrico, hardware mecânico, equipamento, etc.) ou outra classificação qualquer para detalhar melhor a proposta. Note que os gráficos confrontam a proposta de revisão do ES com o ES atualmente cadastrado no sistema (o valor do ES é calculado multiplicando-se o ES pelo preço do item).

A revisão pode estar sugerindo um aumento do ES, mas a empresa pode estar necessitando reduzir custos. Da mesma forma, a revisão pode estar sugerindo uma redução do ES, mas a alta direção pode ter identificado uma possibilidade de falta de hardware (por exemplo) no mercado e reduzir os estoques pode ser uma decisão suicida. Que decisão tomar? Este é o papel do médio escalão e da alta direção nesta etapa. Em muitas situações, no entanto, o ponto de vista estratégico da análise pode se resumir a uma análise mais operacional sobre a disponibilidade ou não de recursos no orçamento para a implementação da proposta (caso ela represente um aumento de estoque). Por não terem um conhecimento muito profundo dos itens e nem tempo para uma análise detalhada, o médio escalão e a alta direção privilegiarão unidades de análise mais agregadas, tais como aquelas da Figura 2.

É importante que os dois grupos tenham consciência que nesta etapa a questão central é confrontar uma decisão de estoque (a revisão do ES) com questões estratégicas da empresa, visando garantir que a proposta de revisão do ES esteja alinhada com as estratégias funcionais e competitiva. Usar a cobertura de demanda como única referência para a decisão de qual ES adotar é um erro comum, conforme Corrêa e Corrêa (2007) chamam a atenção.

Caso a proposta não seja aprovada por um dos dois grupos (ou pelos dois), há duas alternativas: podem solicitar uma nova proposta, sugerindo alterações, ou podem exercer seu poder de veto e impor uma política de ES ligeiramente ou totalmente diferente daquela proposta pela etapa anterior (ou mesmo manter o ES atual, sem alteração). No primeiro caso, o processo volta para a etapa anterior e o grupo multifuncional deve analisar a viabilidade e os riscos que estariam relacionados às alterações sugeridas pelos gerentes e/ou alta direção ou buscar levantar as ações (bem como prazos, recursos e responsáveis) que seriam necessárias 
para se adotar estas sugestões. Neste caso, o processo fica em um looping até que um consenso seja alcançado (geralmente isto acontece até a segunda tentativa). Quanto ao segundo caso, ainda que seja perfeitamente aceitável que os dois grupos imponham uma modificação pequena na proposta apresentada, uma grande alteração só teria sentido se estivesse embasada em questões estratégicas fortes, caso contrário, os gerentes e a alta direção, com (teoricamente) menos competência para discutir sobre questões técnicas e problemas diários enfrentados pela operação, estariam cometendo um dos erros mais comuns no processo de definição do ES, conforme já citado: definir o ES por "feeling".

Após ter recebido a primeira aprovação (a do grupo dos gerentes funcionais), caso o impacto da revisão do ES (para mais ou para menos) não seja significativa, a segunda aprovação (a da alta direção) poderia ser desprezada. Podem ser combinados, aliás, critérios a partir dos quais o primeiro grupo teria autonomia para, sozinho, decidir sobre a proposta.

\section{a) Classificação $A B C$}

Vale, por fim, uma observação quanto à classificação $\mathrm{ABC}$ (Figura 2). Sugere-se que seja adotado o critério preço $\times$ demanda média futura do item, considerando-se que a demanda futura está disponível no sistema da empresa e é mais representativa que o consumo passado.

É comum encontrar itens com baixo preço, mas que são consumidos em grandes quantidades, o que significa que o valor financeiro consumido por semana ou por mês é alto. Este critério evidencia este tipo de item. Por outro lado, este critério pode fazer com que um item muito caro (classe A), mas com baixíssima demanda (um item opcional, por exemplo), seja classificado em uma classe inferior (um item caro com demanda média mensal de 0,25 peça por mês, por exemplo, poderia ser classificado como B ou C). Para evitar este problema, sugere-se que os limites inferiores das classes A e B (ou seja, os limites a partir dos quais os itens serão classificados como B ou A) sejam definidos pelo critério preço $\times$ demanda média futura, mas que a definição da classe de cada item use como critério o maior entre os dois valores seguintes: preço do item e preço $\times$ demanda média futura do item. Pelo fato de se utilizar dois critérios diferentes para os limites das classes e para a classificação dos itens, poder-se-ia imaginar que isto iria causar uma distorção no número esperado de itens em cada classe. Mas na prática esta distorção costuma ser insignificante.

É importante que a classificação $\mathrm{ABC}$ dos itens seja conhecida já na segunda etapa.

\subsubsection{Contato com o fornecedor e cadastro do Estoque de Segurança no sistema}

Após a proposta de revisão do ES ter sido aprovada na etapa anterior, os dados do ES devem ser carregados no
Distribuição do número de itens em relação à cobertura de demanda

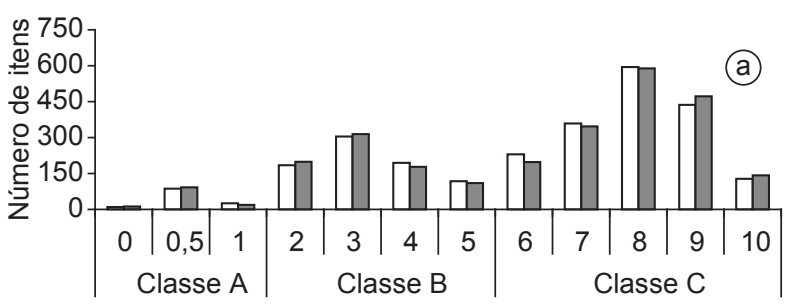

Cobertura de demanda do ES (em semanas)

口ES atual $\square E S$ proposto

Distribuição do valor $(\mathrm{R} \$)$ do $E S$ em relação à cobertura de demanda

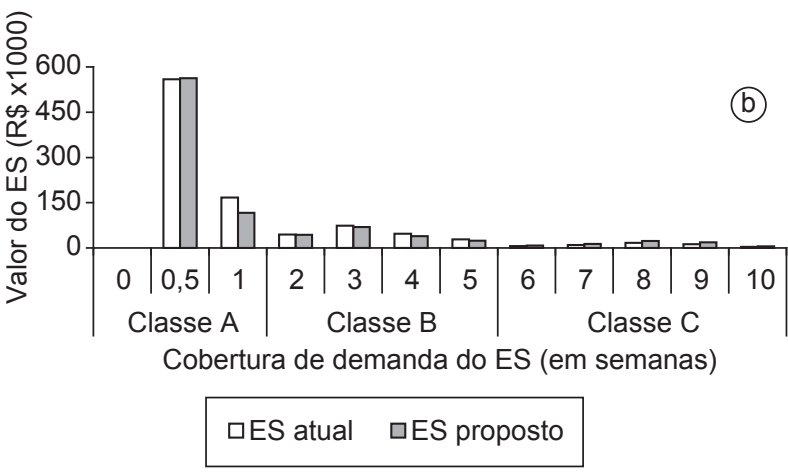

Comparação entre o ES atual e o ES proposto em relação à classe do item

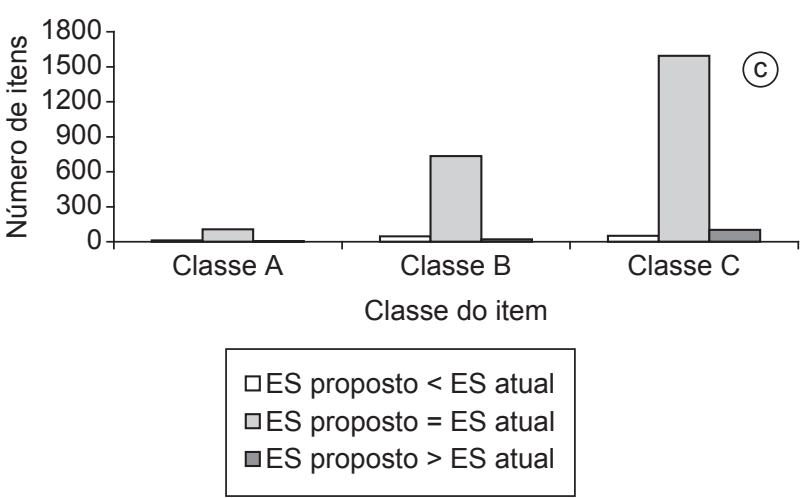

Figura 2. Critérios para a análise da revisão do ES na terceira etapa do modelo.

sistema pelo pessoal de Tecnologia de Informação (TI). No entanto, é imprescindível que antes disso as alterações sejam comunicadas aos fornecedores envolvidos, pois em uma revisão de ES típica, uma parte do ES sofre aumento, outra sofre redução e outra não sofre alteração (é mantido o ES atualmente cadastrado no sistema). Nos dois primeiros casos haverá impacto nas quantidades compradas (uma redução do ES significa menos compras, pois parte da demanda será atendida pela parte do estoque que deixará 
de ser ES). Em muitos casos, pode até ser necessária uma negociação com o fornecedor para estabelecer um prazo para a implementação das mudanças. O objetivo principal desta etapa é evitar a amplificação da incerteza ao longo da cadeia (efeito Forrester; ver: MOYAUX; CHAIB-DRAA; D'AMOURS, 2007; PAIK; BAGCHI, 2007).

\subsubsection{Monitorando o Estoque de Segurança e seu desempenho}

Após a definição (ou revisão) do ES e, logicamente, a execução das ações necessárias para transformá-lo em estoque físico, é imprescindível medir seu desempenho visando monitorar sua habilidade em atender a seus objetivos: reduzir a probabilidade de falta, mas sem excesso de estoque. Isto é necessário porque o leque de variáveis e dados usados no seu processo de definição pode refletir uma realidade diferente, em alguma medida, da realidade atual. Desta forma, o nível de serviço considerado no processo de definição do parâmetro pode não ser atingido na prática, por conta de mudanças (aleatórias ou não) nas variáveis que influenciam o ES. Inclusive, o ES calculado, cadastrado no sistema e formado fisicamente pode se mostrar, mais tarde, superdimensionado. Por exemplo, quando um fornecedor consegue melhorar seu desempenho por conta de ações autônomas, mas os dados que foram usados no cálculo do ES foram coletados antes das ações surtirem efeito. Sem os indicadores, esta situação provavelmente só seria identificada na próxima revisão do ES. Assim, além daquela revisão planejada e sempre realizada segundo uma periodicidade preestabelecida, estes indicadores podem mostrar a necessidade de uma revisão adicional do ES.

São sugeridos três indicadores, explicitados a seguir (sugere-se que eles fiquem sob responsabilidade das mesmas pessoas responsáveis pela primeira etapa). $\mathrm{O}$ primeiro é reativo e os dois últimos, por permitirem algum tempo de reação, têm um caráter preventivo. Todos os três precisam de dados de entrada que deverão ser obtidos do sistema de informação da empresa (ERP, por exemplo). Os indicadores podem ser gerados fora do sistema, mas o ideal é que estejam a ele integrados (mesmo que sejam gerados sob a forma de relatórios de texto). Porém, isto vai depender da flexibilidade (nível de customização) oferecida pelo sistema.

\section{a) Nível de falta}

Este indicador mostra os itens faltantes e suas respectivas quantidades em falta ao longo do tempo. Apesar de mostrar a informação quando já é tarde demais (o item já está em falta), ele indica os itens que precisam ter seu ES revisado ou analisado com mais cuidado, pois, caso o ES do item tenha sido calculado, formado fisicamente e ainda assim o item faltou, pode ser que algumas variáveis importantes não tenham sido consideradas durante o processo de definição do parâmetro.

Além disso, com este indicador pode-se formar um banco de dados sempre útil, principalmente em empresas que operam sua produção em ambientes mais voláteis: $o$ histórico de faltas por item. Por meio dele é possível obter informações sobre os fornecedores mais problemáticos, as tecnologias mais faltantes (matéria-prima, equipamento, item estrutural, etc.), a frequência da falta (quantas vezes o item faltou em um dado período) e sua duração (quanto tempo o item ficou indisponível cada vez que faltou), entre outras. Estas informações, por sua vez, são úteis ao se fazer inferências, durante a análise do grupo multifuncional, sobre a causa da falta e sobre a possibilidade dela voltar a ocorrer (se a variável que causou a falta não estiver sob controle da empresa).

\section{b) Uso do Estoque de Segurança}

Este indicador foi baseado no enfoque evolutivo proposto por Corrêa e Corrêa (2007) para "calibrar" o ES.

O ES é uma quantidade comprada a mais. Desta forma, se tudo acontecesse conforme o planejado, o ES nunca seria utilizado, assim, sempre haveria em estoque no mínimo uma quantidade igual ao ES. Mas esta é uma situação hipotética, pois na prática é comum o ES ser consumido parcialmente ou totalmente por conta das ocorrências não planejadas existentes em um ambiente industrial.

A ideia por trás deste indicador é simples: monitorar o estoque do item continuamente, observando com mais cuidado e atuando (se for necessário) no caso dos itens cujo nível de estoque fica sempre acima do ES ou tende a ficar sempre muito próximo de zero.

Conforme ilustrado na Figura 3, o item A tem um comportamento tal que seu nível de estoque está sempre acima do ES, ou seja, o ES nunca chega a ser consumido. Neste caso, poderia ser considerada a possibilidade de diminuição do ES. Já no caso do item B, a situação é inversa: seu ES está sempre sendo utilizado e, mesmo que o item ainda não tenha faltado (portanto, o indicador anterior não pode identificá-lo), o fato de estar sempre com um nível de estoque próximo de zero pode subsidiar uma decisão de aumento do ES, mesmo que temporária (se for um item crítico e barato, o aumento do ES poderia ser adotado de forma paliativa, visando não colocar em risco o atendimento, até que a causa do problema do consumo acima do esperado seja eliminada).

\section{c) Margem de Segurança}

Conforme já explicitado, um ES tem sempre uma cobertura de demanda implícita ao seu valor. Considerando que os tipos de empresas que são o foco deste trabalho têm sua demanda sujeita a uma série de incertezas que resultam em variações desta demanda ao longo do tempo, isto significa que a cobertura de demanda oferecida pelo 

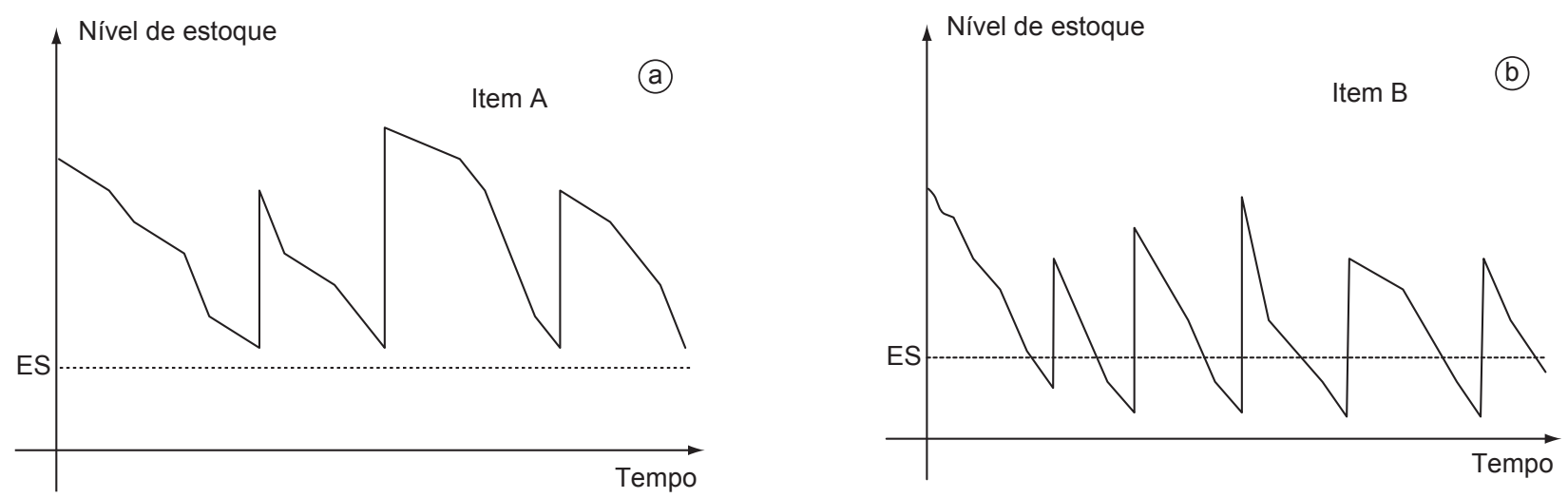

Figura 3. Dois itens com comportamentos distintos em termos do nível de estoque.

ES também varia ao longo do tempo. Por exemplo: um item que tem um ES igual a 10 peças tem uma cobertura correspondente a 1 mês caso sua demanda média (mensal, por exemplo) seja igual a 10 peças. Caso sua demanda média suba para 20 peças (por conta de um acréscimo considerável no plano de produção ou porque o item passou a ser componente de um número maior de montagens), o mesmo ES passará a oferecer uma nova cobertura igual a 0,5 mês (ainda que seja apenas um exemplo, grandes variações na demanda dos itens não são difíceis de acontecerem neste tipo de empresa, principalmente em níveis inferiores da estrutura de produto e quando se trata de matéria-prima). Nesta segunda situação, a segurança oferecida pelo mesmo ES pode não ser mais suficiente. Desta forma, o objetivo deste indicador é identificar itens que sofreram variações consideráveis na cobertura de demanda oferecida pelo ES e, desta forma, antecipar a revisão do parâmetro visando adequá-lo para que continue garantindo o mesmo nível de serviço desejado.

O indicador, desenvolvido pelo autor e ilustrado na Figura 4, é operacionalizado da seguinte forma: sempre que ocorre uma revisão de ES, é calculada, para cada item, a cobertura de demanda que o ES cadastrado oferece. Após isto e antes que uma nova revisão planejada do ES ocorra, são calculadas periodicamente (sugere-se uma periodicidade mensal) as coberturas de demanda do ES ao longo do tempo. Para isto, divide-se o ES cadastrado pela demanda média (futura) referente a cada período. Quando a cobertura sair de uma faixa pré-determinada (a margem de segurança, em percentagem), o item é identificado e seu ES analisado visando decidir pela sua alteração ou não. Por não existir uma regra específica para a definição da margem de segurança, ela deve ser definida qualitativamente entre os envolvidos no processo de definição do ES.

Pela Figura 4, quando foi revisado o ES dos itens A e B (no período 1) eles ofereciam uma cobertura de, respectivamente,
1 e 1,5 mês. Conforme o tempo foi passando, a demanda média do item $\mathrm{A}$ foi diminuindo e a do $\mathrm{B}$, aumentando. Depois de quatro meses a cobertura de demanda do ES dos dois itens saiu da margem de segurança definida em $20 \%$. Nestes casos, o indicador serve para sinalizar que, em função das variações que as demandas sofreram, o primeiro item pode estar com um ES superdimensionado e o segundo, subdimensionado.

\section{Limitações do trabalho}

A proposta apresentada é resultado da experiência do autor na indústria, trabalhando com atividades relacionadas às áreas de compras e planejamento de materiais. Mas, ainda que várias das etapas que constituem o modelo proposto tenham sido aplicadas na prática com relativo sucesso, na época em que isto ocorreu o processo todo não sofreu uma observação crítica, cientificamente falando, que permita caracterizar estas aplicações como "pesquisas de campo" que serviriam para validar o modelo. Além disso, o modelo que foi usado na prática como referência sofreu aperfeiçoamentos - com base nos resultados obtidos na época - até transformar-se neste que foi apresentado. Assim, ao ter como principal contribuição apresentar um modelo teórico para o processo de definição do ES, o autor espera que outros trabalhos possam aplicá-lo integralmente e com observação crítica científica.

Existem duas questões que não foram tratadas neste trabalho, mas que, por suas extensões talvez faça mais sentido tratá-las em um artigo específico. Referem-se a: onde manter o ES e quem deve "pagar a conta". Partindo-se do princípio que as incertezas nos ambientes interno e externo geram a necessidade de ES, faz sentido defender que o agente causador da incerteza deveria se responsabilizar pelo custo do ES, quando isto for possível. Assim, ainda que a falta de alumínio no mercado force uma empresa que precise deste insumo a manter ES, assumindo ela própria 

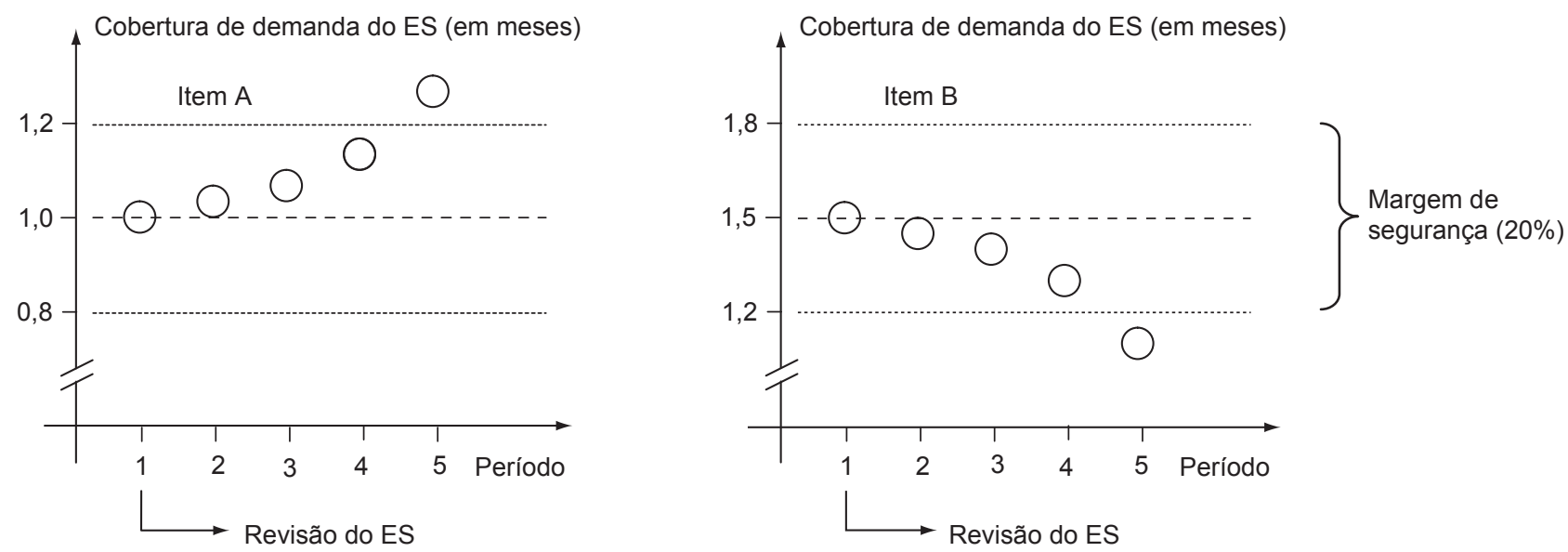

Figura 4. O conceito da margem de segurança da cobertura de demanda do ES.

o seu custo, quando existe uma incerteza relacionada ao fornecimento (atraso, por exemplo), é justificável que a empresa compradora discuta com seu fornecedor a manutenção de um ES sob sua responsabilidade. Estas questões, no entanto, não invalidam a proposta apresentada, pois ela responde quanto manter de ES e quais itens precisam de ES, independentemente de onde o ES será mantido e de quem arcará com seu custo.

\section{Considerações finais}

$\mathrm{Na}$ verdade, o que o modelo proposto de definição do parâmetro ES tenta construir é um planejamento colaborativo, em que diferentes funções participam de uma decisão que, pelo ponto de vista que embasou todo este trabalho, perde em qualidade e fica incompleta caso seja puramente quantitativa, puramente qualitativa ou restrita a uma única função. Neste sentido, considerando a evolução da abordagem da Gestão da Cadeia de Suprimentos e sua importância, o último estágio desta colaboração deve englobar também os fornecedores.
Por fim, é importante fazer algumas sugestões finais sobre o processo de definição do ES:

- (i) Privilegiar processos de análise de ES transversais, ou seja, aqueles que englobam diferentes funções e diferentes pontos da cadeia de suprimentos. Assim, com as decisões mais robustas, pode-se evitar uma possível duplicação da segurança (por exemplo, haver ES de um mesmo item na empresa e no fornecedor) e, o que é mais importante, pode-se identificar e atuar com mais clareza nas causas das incertezas que geram a necessidade do ES.

- (ii) Na definição ou revisão de um ES, não se deixar influenciar por eventos pontuais ou muito específicos cuja probabilidade de reincidência é pequena.

- (iii) A análise do impacto financeiro de uma revisão de ES (terceira etapa do modelo) pode (na verdade, deve) ser acompanhada de uma análise global dos estoques da empresa, já que o ES é apenas uma parcela do montante.

\title{
A proposal for the process of definition of safety stock of purchased items for make-to-order companies that manufacture complex products
}

\begin{abstract}
The definition of Safety Stock usually follows only qualitative criteria, which most of the times do not have any conceptual foundation, or only quantitative criteria, which does not make actual good use of the knowledge of essential people involved. Based on the author's practical experience and with the support of the literature, this paper presents a model for the definition of this parameter based on these two criteria, at the same time. It is expected it can support the decisions related to the definition of Safety Stock of purchased items for make-to-order companies that manufacture complex products, in which this kind of item accounts for most of the cost of the final product. Uncertainties in the internal and external environment of these companies make this kind of stock necessary in a lot of situations.
\end{abstract}

Keywords: Safety Stock. Make-to-order. Complex products. 
BALLOU, R. H. Gerenciamento da cadeia de suprimentos: logística empresarial. 5 ed. Porto Alegre: Bookman, 2006.

CORRÊA, H. L.; CORRÊA, C. A. Administração de produção e operações. 2 ed. São Paulo: Atlas, 2007.

CORRÊA, H. L.; GIANESI, I. G. N.; CAON, M. Planejamento, programação e controle da produção. 5 ed. São Paulo: Atlas, 2007.

FISHER, M. L. What is the right supply chain for your product? Harvard Business Review, v. 75, n. 2, p. 105-116, 1997. Disponível em: <http://www.apparelandfootwear.org/UserFiles/File/ Presentations/What\%20is\%20the 20right\%20supply\%20chain. pdf>. Acesso em: Julho 2009.

GAITHER, N.; FRAZIER, G. Administração da produção e operações. 8 ed. São Paulo: Pioneira Thomson Learning, 2002.

HENDRICKS, K. B.; SINGHAL, V. R.; STRATMAN, J. K. The impact of enterprise systems on corporate performance: a study of ERP, SCM, and CRM system implementations. Journal of Operations Management, v. 25, n. 1, p. 65-82, 2007. Disponível em: <http://www.sciencedirect.com/>. Acesso em: Julho 2009.

HOLWEG, M. The genealogy of lean production. Journal of Operations Management, v. 25, n. 2, p. 420-437, 2007. Disponível em: <http://www.lean.org/Community/Registered/ArticleDocuments/ Holweg_Genealogy\% 20of\%20Lean\%20Production_JOM_2007. pdf>. Acesso em: Julho 2009.

HOPP, W. J.; SPEARMAN, M. L. To pull or not to pull: what is the question? Manufacturing and Service Operations Management, v. 6, n. 2, p. 133-148, 2004. Disponível em: <http://msom.journal. informs.org/cgi/reprint/6/2/133>. Acesso em: Julho 2009.

HORNG, T. C. A comparative analysis of supply chain management practices by Boeing and Airbus: long-term strategic implications. Massachusetts, 2007. 140 p. Dissertação (Mestrado em Ciência no Transporte) - Massachusetts Institute of Technology - MIT. Disponível em: <http://dspace.mit.edu/handle/1721.1/38579>. Acesso em: Julho 2009.

HUMAIR, S.; WILLEMS, S. P. Optimizing strategic safety stock placement in supply chains with clusters of commonality. Operations Research, v. 54, n. 4, p. 725-742, 2006. Disponível em: <http://or.journal.informs.org/cgi/reprint/54/4/725>. Acesso em: Julho 2009.

LEMOS, F. O.; FOGLIATTO, F. S. Modelagem estocástica do estoque de itens revisados periodicamente com pedidos sujeitos a múltiplas datas de entrega. In: ENCONTRO NACIONAL DE ENGENHARIA DE PRODUÇÃO - ENEGEP, 24, 2004. Anais... Florianópolis: $A B E P R O, 2004$. p. 17-24.

MACIEIRA, A. R. et al. Desenvolvimento e implantação de modelo de gestão de estoques para as Unidades Locais de Saúde da cidade de
Florianópolis. In: ENCONTRO NACIONAL DE ENGENHARIA DE PRODUÇÃO - ENEGEP, 24, 2004. Anais... Florianópolis: ABEPRO, 2004. p. 125-132.

MARUCHECK, A. S.; McCLELLAND, M. K. Strategic issues in make-to-order manufacturing. Production and Inventory Management Journal, v. 27, n. 2, p. 82-96, 1986.

MOYAUX, T.; CHAIB-DRAA, B.; D'AMOURS, S. Information sharing as a coordination mechanism for reducing the bullwhip effect in a supply chain. IEEE Transactions on Systems, Man, and Cybernetics, v. 37, n. 3, p. 396-409, 2007. Disponível em: $<$ http://ieeexplore.ieee.org/xpls/abs_all.jsp?arnumber=4154948>. Acesso em: Julho 2009.

PAIK, S. K.; BAGCHI, P. K. Understanding the causes of the bullwhip effect in a supply chain. International Journal of Retail and Distribution Management, v. 35, n. 4, p. 308-324, 2007. Disponível em: <http://www.emeraldinsight.com/Insight/ viewContentItem.do? contentType=Article\&cntentId=1595350>. Acesso em: Julho 2009.

PARKY, K.; KUSIAK, A. Enterprise resource planning (ERP) operations support system for maintaining process integration. International Journal of Production Research, v. 43, n. 19, p. 3959-3982, 2005. Disponível em: <http://www.icaen.uiowa.edu/ ankusiak/Journalpapers/K_Park.pdf>. Acesso em: Julho 2009.

SANTOS, A. M.; RODRIGUES, I. A. Controle de estoque de materiais com diferentes padrões de demanda: estudo de caso em uma indústria química. Gestão e Produção, v. 13, n. 2, p. 223-231, 2006.

SHINGO, S. O sistema Toyota de produção sob o ponto de vista da Engenharia de Produção. 2 ed. Porto Alegre: Bookman, 1996.

STEVENSON, W. J. Administração das operações de produção. 6 ed. Rio de Janeiro: Livros Técnicos e Científicos, 2001.

VANTEDDU, G. et al. Supply chain focus dependent safety stock placement. International Journal of Flexible Manufacturing Systems, v. 19, n. 4, p. 463-485, 2007. Disponível em: <http:// www.springerlink.com/content/82447211g4518k72/>. Acesso em: Julho 2009.

WEMMERLÖV, U. Assemble-to-order manufacturing implications for materials management. Journal of Operations Management, v. 4, n. 4, p. 347-368, 1984. Disponível em: <http://www.sciencedirect. com/>. Acesso em: Julho 2009.

$\mathrm{XU}, \mathrm{H}$. et al. Data quality issues in implementing an ERP. Industrial Management and Data Systems, v. 102, n. 1, p. 47-58, 2002. Disponível em: <http://www.emeraldinsight.com/Insight/ viewContentItem.do;jsessionid=D18C394493BEF073D828 DF2F3DBC6428? content Type $=$ Article $\&$ contentId $=850065>$. Acesso em: Julho 2009.

\section{Sobre o autor}

\section{João Henrique Lopes Guerra}

Departamento de Engenharia de Produção da Universidade Federal de São Carlos Rodovia Washington Luís, km 235 - SP-310, CEP 13565-905, São Carlos - SP - Brasil e-mail: jhlg2000@ig.com.br 